\title{
ECOLOGÍA POLÍTICA DE LOS DESASTRES: VULNERABILIDAD, EXCLUSIÓN SOCIO-TERRITORIAL Y ERUPCIONES VOLCÁNICAS EN LA PATAGONIA CHILENA
}

HUGO ROMERO TOLEDOa \& HUGO ROMERO ARAVENA ${ }^{b}$

\begin{abstract}
RESUMEN
Los estudios de las ciencias sociales sobre desastres en Chile han ido emergiendo de manera incipiente, debido a la serie de fenómenos que han afectado al país en los últimos años, tales como erupciones volcánicas, terremotos y tsunamis, grandes temporales, sequías e incendios forestales, y que tienen relación con elementos sociales, políticos, económicos, culturales y ambientales. El presente artículo analiza desde la ecología política cómo la vulnerabilidad y la exclusión social y territorial, contribuyen a la generación de desastres socio-naturales, específicamente en la Patagonia chilena. Los casos que se presentan son las erupciones de los volcanes Hudson (localizado en la Región de Aysén) y Chaitén (emplazado en la región de Los Lagos), caracterizadas por la falta de información sobre los territorios afectados, que se interpreta como producto de la territorialización tardía del Estado Chileno. Este hecho ha tenido consecuencias políticas y ecológicas negativas en el actuar de las instituciones públicas frente a los eventos mencionados, aumentando los niveles de vulnerabilidad, pero al mismo tiempo fortaleciendo la resiliencia comunitaria.
\end{abstract}

PALABRAS CLAVE: Ecología Política, Desastres Socio-naturales, Patagonia Chilena, Erupciones Volcánicas, Hudson, Chaitén.

POLITICAL ECOLOGY OF DISASTERS: VULNERABILITY, SOCIO-TERRITORIAL EXCLUSION AND VOLCANIC ERUPTIONS IN CHILEAN PATAGONIA

\section{ABSTRACT}

The studies of disasters from social sciences have been emerging in Chile because of the phenomena that have affected the country in recent years, such as volcano eruptions, earthquakes and tsunamis, large storms, drought and fires, which are related with social, political, economic, cultural and environmental elements. This article analyzes from political ecology how vulnerability, and social and territorial exclusion,

a Director del Observatorio Regional, Universidad Católica de Temuco. Investigador Asociado al Instituto de Investigación en Ciencias Sociales, Universidad Diego Portales. Investigador Adjunto del Centro de Estudios de Conflicto y Cohesión Social (COES). hugo.romero@uct.cl

b Investigador Responsable Centro de Investigación de Vulnerabilidades y Desastres Socionaturales (CIVDES) www.civdes.uchile. cl. Profesor del Departamento de Geografía de la Universidad de Chile. hromero@uchilefau.cl 
contributes to the generation of socio-natural disasters, especially in Chilean Patagonia. The cases that presents are the eruption of Hudson volcano (located in the Aysén Region) and Chaitén volcano (located in Los Lagos Region), both events characterized because of the lack of information about the territories that were affected, which is interpreted as a consequence of the late territorialization of the Chilean State. This fact has had negative political and ecological consequences in the action of public institutions to face this kind of events, raising the levels of vulnerability, while strength community resilience.

KEY WORDS: Political Ecology, Socio-natural Disasters, Chilean Patagonia, Volcano Eruptions, Hudson, Chaitén.

\section{INTRODUCCIÓN}

Los estudios de las ciencias sociales sobre desastres en Chile han ido emergiendo de manera incipiente, debido a la serie de fenómenos que han afectado al país en los últimos años. Algunos de ellos han sido las erupciones de los volcanes Hudson (1991) Llaima (2008), Chaitén (2008), Puyehue-Cordón del Caulle (2011) y Copahue (2012); los terremotos de Tarapacá (7,8 $8^{\circ}$ Richter, $2005)$, Aysén $\left(6,2^{\circ}, 2007\right)$, Tocopilla $\left(7,7^{\circ}, 2007\right)$, el gran terremoto y tsunami del Centro-Sur $\left(8,8^{\circ}\right.$, 2010) y sus réplicas de $6,9^{\circ}$ (2010), 6,9 y 7,0 (2011), Vallenar $\left(6,8^{\circ}, 2013\right)$ y el terremoto del Norte Grande $\left(8,2^{\circ}\right.$ y $\left.7,6^{\circ}, 2014\right)$. A ello se deben agregar los efectos de grandes temporales, como el que afectó al Centro-Sur el año 2006, que inundó entre otras a la ciudad de Concepción, y los registrados en marzo de 2015, cuyos aluviones y deslizamientos de tierras devastaron la porción sur del Desierto de Atacama; la sequía que se arrastró por seis años desde 2008, mermando la agricultura y la capacidad de generación de energía hidroeléctrica y los incendios forestales que todos los años afectan igualmente a los habitantes de ciudades contiguas a grandes extensiones de bosques del Centro y Sur del país. Todos estos desastres han impactado a la sociedad chilena, obedeciendo a causas sociales, políticas, económicas, culturales y ambientales.

Chile es un país extenso, compuesto por climas, relieves y características geológicas distintas y variadas. Desde el punto de vista climatológico está fuertemente expuesto a los efectos del Anticiclón del Pacífico Sur, el Monzón Amazónico, y al Frente Polar, producto de lo cual tiene al clima más árido del planeta en el Desierto de Atacama, y al mismo tiempo, climas glaciales que explican los grandes cuerpos de agua dulce de la Patagonia. La Cordillera de los Andes actúa como biombo climático, separando las situaciones chilenas de las del resto de Sudamérica, acumulando, lluvias, nieves y hielos en sus cumbres, permitiendo con ello la irrigación de los valles y la existencia de ríos torrentososque recorren cortos trechosy pendientes inclinadas hasta llegar al mar. Su población, producto de los patrones de colonización, está fuertemente concentrada en las regiones centrales, dentro de las fronteras del antiguo Reino de Chile, dejando a los extremos escasamente poblados. Este hecho demográfico y geopolítico es altamente significativo en cuanto a la vulnerabilidad ante las amenazas naturales que tiene el país, las reflexiones teóricas y empíricas que las analizan, y las políticas públicas para enfrentarlos. Como los riesgos de desastres son producto de la superposición en el tiempo y el espacio de las amenazas naturales de los paisajes y de la vulnerabilidad social de los habitantes de esos lugares, se puede afirmar que Chile está constantemente afectado por desastres socionaturales. Dentro de éstos, han sido la erupción del Volcán Chaitén en 2008, el terremoto y tsunami de 2010, el gran incendio de Valparaíso de 2014, y las inundaciones del Desierto de Atacama de 2015, los fenómenos que más han despertado recientemente el interés público.

La interrelación entre centralización y exclusión social y espacial aflora siempre cuando se trata de evaluar la prevención, enfrentamiento y reconstrucción ante los desastres socionaturales que afectan a Chile recurrentemente. Estos componentes geográficos están lejos de constituir un fenómeno natural o neutral, para corresponder más bien a patrones político-ecológicos que afectan de manera desigual a la sociedad chilena, especialmente a aquellos sectores más vulnerables, que en gran medida ya se encuentran social, económica y territorialmente excluidos antes que se registren los desastres. 
El presente artículo analiza desde la ecología política cómo la vulnerabilidad y la exclusión social y territorial, contribuyen a la generación de desastres socio-naturales, específicamente en la Patagonia chilena. Su estructura se divide en cuatro partes. En la primera sección se presenta la aproximación teórica de la ecología política con sus principales análisis, y se introduce la discusión sobre desastre, riesgo, vulnerabilidad y resiliencia. En la segunda sección se considera la exclusión social y territorial de la Patagonia como marco de referencia para entender la vulnerabilidad de dicho espacio. En la tercera parte se analiza la erupción de los volcanes Hudson (1991) y Chaitén (2008), desde una descripción de la catástrofe y sus impactos ambientales y sociales basados en el análisis de fuentes secundarias, principalmente documentos históricos, informes institucionales, artículos científicos y prensa escrita. De acuerdo a Castree et al. (2009) y Demeritt (2009), las relaciones ambientales que interesan a la geografía, se refieren a asociaciones específicas entre atributos o dimensiones de la sociedad y de la naturaleza, que pueden ser tratadas también como objeto de análisis independiente por las ciencias sociales y naturales. En nuestro caso, el medioambiente es entendido como entorno, pero también como unidad de análisis. En la última parte se ofrece una conclusión que sintetiza los argumentos y los hallazgos.

\section{Ecología Política}

A partir de los 1980s, las ciencias sociales, empujadas por la necesidad universal de entender la "crisis ambiental" y dar cuenta del surgimiento de movimientos socio-ambientales, comenzaron a desarrollar perspectivas para estudiar las complejas interrelaciones entre la sociedad y la naturaleza (Braun \& Castree, 1998; Castree \& Braun, 2001). Desde los 1990s, aparecieron discursos dominantes sobre el medioambiente, amparados en instituciones multilaterales como Naciones Unidas, el Banco Mundial y el Grupo de los 8 (G8), que buscaron reconciliar el crecimiento económico y la sustentabilidad ambiental. De esta manera, una serie de conceptos emergieron para "gestionar", "manejar" o "adaptar" las sociedades a los fenómenos naturales, sin trastocar en profundidad los modelos políticos y económicos que gobiernan a la sociedad global (Escobar, 1996, 1999). Dentro de este debate surgió la ecología política, como un campo fértil y crítico donde confluyen elementos de la economía política, los estudios culturales, la geografía, la antropología y la sociología ambiental, con el fin de cuestionar discursos y prácticas hegemónicas sobre la sociedad y la naturaleza, y al mismo tiempo resaltar el carácter conflictivo de las transformaciones ambientales y sus profundas raíces en problemas sociales, étnicos, de género y de distribución geográfica del poder (Peet et al. 2011; Robbins, 2011).

En sus treinta años de evolución, la ecología política se ha nutrido de tres grandes vertientes, muchas veces interrelacionadas. La primera está influenciada por la economía política, derivada del análisis de Blaikie \& Brookfield (1987) y luego profundizada por elementos de la geografía crítica, que se centra en estudiar al cambio ambiental como resultado de contradicciones sociales, políticas y económicas, que tienen efectos sobre el control y uso de recursos naturales, principalmente en el Tercer Mundo (Bryant \& Bailey, 1997). La segunda corriente, incorpora elementos del postestructuralismo (Escobar, 1996, 1999), enfocada en cómo se crean, legitiman y contestan narrativas medioambientales, que incluyen lenguaje, ciertos tipos de conocimiento y prácticas, que están social y políticamente situadas (Sullivan \& Stott, 2000; Peet \& Watts, 1996). Esta segunda corriente pondrá atención en narrativas y prácticas locales sobre el uso alternativo de recursos, y cómo se confronta el poder del Estado a través de luchas sociales que le dan voz a los excluidos (Peet et al. 2011). Una tercera vertiente, más actual, está incorporando elementos de la teoría actor-red (ANT por sus siglas en inglés) y del post-humanismo, para entender la relación entre el mundo humano y el no-humano (Latour, 2004; Whatmore, 2006), principalmente centrado en cómo las cosas y la materia, poseen una "vitalidad" que no puede ser totalmente entendida desde la economía política y los estudios culturales. En esta última corriente, ciertas materialidades tienen el poder de no solamente impedir o bloquear la acción humana, sino también de "actuar" como cuasi-agentes, con trayectorias, propiedad y tendencias propias (Bennet, 2010). 
La adopción de un enfoque de ecología política implica ampliar el entendimiento de las relaciones ambientales, sociales y naturales, para comprender como estas se interrelacionan, co-constituyen y se afectan. De esta manera, los fenómenos naturales no pueden ser analizados sin considerar las relaciones sociales y las construcciones culturales; pero también, la naturaleza no puede ser entendida como algo estático y pasivo, sino como un actante en movimiento que afecta y co-determina la acción social.

\section{Desastres, Riesgo, Vulnerabilidad y Resiliencia}

La literatura sobre la relación entre ecología política y desastres es abundante y rica en análisis, principalmente debido a que estos últimos se concentran en el Tercer Mundo. No es nuestra intención hacer una revisión acabada de estos análisis, pero sí señalar los principales conceptos que ocupa, para reflexionar sobre su posible aplicación al caso chileno. La principal máxima de este tipo de estudios es que los eventos naturales extremos forman parte del ciclo natural de la tierra, y pasan a transformarse en riesgo solo cuando la población se asienta en los lugares dónde, y los tiempos cuándo ellos ocurren. Los desastres naturales no son el mayor riesgo que amenaza a la humanidad. En efecto, conflictos violentos, enfermedades y hambrunas, afectan más personas, y por tiempo más prolongado, que los terremotos, erupciones volcánicas o epidemias, por ejemplo. El riesgo y las amenazas naturales que enfrenta la población no pueden ser separados de las condiciones y circunstancias político-económicas en la que ella está inserta (Wisner et al. 2005). De esta manera, lo "natural" y lo "social" no pueden ser entendidos en forma independiente, sino como fenómenos multidimensional y profundamente conectados. Amenazas naturales, vulnerabilidades y riesgos, están interrelacionados con factores socioeconómicos, políticos, culturales y ambientales de carácter histórico, que distribuyen a la población y sus características biofísicas, de forma desigual sobre el territorio.

\section{Riesgos y Desastres}

Los desastres, por lo general, no son el resultado "de las violentas fuerzas de la naturaleza" o de "un capricho de la naturaleza". Tampoco son el resultado del crecimiento de la población o de la falta de "modernización" para controlar a la naturaleza: los desastres son la combinación entre amenazas naturales y la acción humana (Wisner et al. 2005). La influencia política, los ingresos económicos, el acceso a recursos y al conocimiento, siguen patrones desiguales dentro de la sociedad, que influencian directamente la forma en la cual las amenazas naturales son percibidas y experimentadas. Bajo estas perspectivas críticas, los desastres no son naturales o técnicos, sino que políticos; $y$ aunque su detonante sea natural (tectónico, climático o biológico), son raramente un accidente. Los desastres socio-naturales están fuertemente asociados a las desigualdades generadas por el desarrollo capitalista, que se manifiesta en relaciones humanas-medioambientales no sustentables (Pelling, 2003; Pelling \& Dill, 2010).

Los criterios para la localización, construcción e implementación de los asentamientos humanos, han seguido una lógica político-económica ineficiente y unilateral con respecto a la relación sociedad-naturaleza. De esta forma, a la degradación ambiental propia de la instalación de estos asentamientos, debe sumarse la constante urbanización y re-urbanización de áreas que concentran las amenazas naturales y su expansión, mucha veces de manera informal hacia zonas de riesgo, generando como consecuencia desigualdades socio-territoriales en el espacio urbano (Vidal \& Romero, 2010; Romero \& Vidal, 2014; Romero \& Mendonca, 2012; Romero, et al. 2011, 2010).

Los desastres tienen efectos directos sobre el desarrollo humano: pueden afectar actividades económicas, infraestructura pública y privada, y aumentar la vulnerabilidad social de grupos que ya estaban marginados del crecimiento económico. De esta manera, los desastres socio-naturales están vinculados a factores de vulnerabilidad social como clase, género, etnia, grupo etario, estatus migratorio y segregación socio-espacial, que exponen a la gente a riesgos particulares. De la misma manera, los desastres socio-naturales pueden alterar significativamente la estructura y el comportamiento de una sociedad, generando cambios socio-económicos y socio- 
políticos importantes a lo largo del tiempo. Los desastres socio-naturales pueden ser prevenidos o mitigados, evitando su ocurrencia. Su prevención y mitigación implican cambios en la estructura política, institucional, social, económica, cultural y ambiental de la sociedad (Pelling \& Dill, 2010). Estos cambios son consustanciales a la noción de desarrollo sustentable de una sociedad, dado que constituyen una ventana de oportunidades (Manyena, 2013). De acuerdo a la Conferencia de la Naciones Unidas para la Reducción de los Desastres Naturales, celebrada en marzo de 2015 en Sendai, Japón, de no realizarse estos cambios que aseguren la prevención y la mitigación, los peores desastres están aún por ocurrir.

\section{Vulnerabilidad}

Desde la ecología política, existen tres conceptos interrelacionados para estudiar los riesgos, que parten de la base de la mutua interacción entre sociedad y naturaleza. Estos conceptos son: vulnerabilidad, adaptación y resiliencia (Füssel, 2007; Adger, 2006). La ecología política sostiene que los desastres son el resultado de la vulnerabilidad, entendida como las características o situaciones de una persona o grupo, que influencian su capacidad de anticipar, resistir o recuperarse del impacto de un evento o proceso natural de carácter extremo, que envuelve una serie de factores que determinan la vida y sus formas (organización, información, redes sociales, cultura, tierra y acceso y uso de recursos naturales), la propiedad y otros elementos, que son puestos en riesgo (Wisner et al. 2005, p. 11).

En esta perspectiva, lo que hace vulnerable a las personas es la interrelación, por un lado, entre pobreza, falta de recursos y marginalización, y en segundo lugar, la diversidad diaria de riesgos que existen tanto en los niveles locales como globales. En estos términos, la vulnerabilidad es la exposición desigual al riesgo que hace que ciertas poblaciones sean más propensas al desastre (Bankoff et al. 2004). De esta manera, la vulnerabilidad ante los desastres socio-naturales es, principalmente, una creación humana que depende de la economía política de los recursos (Adger et al. 2005), y por tanto, está estrechamente vinculada al ejercicio del poder político. Estas relaciones de poder están representadas a escalas locales, regionales, nacionales $e$ internacionales, que las conectan con el acceso a toma de decisiones sobre la salud, ingreso, trabajo, vivienda y uso y manejo de los recursos naturales (Wisner et al. 2005). Siguiendo este argumento, desde la ecología política, la vulnerabilidad no es un resultado, sino un estado y una causa preponderante de conflictos sociales (Eakin \& Luers, 2006), los cuáles quedan de manifiesto a través de desastres socio-naturales.

La vulnerabilidad se concentra social y espacialmente en determinados grupos sociales, raciales y étnicos, los cuales son localizados (y se localizan) en espacios expuestos a las amenazas naturales, cuya urbanización ha degradado violentamente el medioambiente, ante una planificación ambiental y urbana débil, desactualizada o inexistente, y de nulas políticas de asentamiento humano. Dichos asentamientos, donde viven y trabajan especialmente los grupos sociales más vulnerables, se caracterizan por formas de vida frágiles, ingresos insuficientes, desigualdades políticas y legales, y falta de protección social ofrecida por el Estado (Bolin, 2006). Esto explicaría por qué existen poblaciones que enfrentan más riesgos, que están menos seguras o que tienen menos capacidades de acción frente a una amenaza natural, debido principalmente a la ocupación desigual del espacio. Los desastres socio-naturales tienen una historia y la vulnerabilidad humana recoge experiencias del pasado sobre espacios que han sido transformados por fuerzas locales y globales. Sin embargo, la falta de certezas sobre la magnitud y frecuencia de las amenazas naturales, junto con la ausencia de planificación urbana y territorial, las herramientas de mitigación generalmente centradas en obras de ingeniería y no sobre la preparación y adaptación de la sociedad, así como la escasa influencia política y económica de estos grupos en la toma de decisiones, les transforma en las principales víctimas de las amenazas naturales.

Bajo esta lógica, la vulnerabilidad acarrea una incapacidad de adaptación, debido a que los individuos y las comunidades están constreñidos por procesos políticos, económicos y sociales que les impiden ajustarse a las perturbaciones provenientes de la naturaleza o de la sociedad. Sin embargo, la capacidad adaptativa también 
depende de elementos locales, como las relaciones de parentesco, las redes sociales que pueden ayudar a absorber el stress, y la capacidad que tengan las instituciones de coordinarse con dichos elementos y las estructuras que gobiernan la sociedad (Smit \& Wandel, 2006). Esta posibilidad de adaptación es comúnmente conceptualizada como resiliencia, que es la capacidad de vincular los sistemas socio-ecológicos para absorber perturbaciones recurrentes, como huracanes $e$ inundaciones, y mantener estructuras esenciales, procesos y retroalimentaciones, a partir de un complejo sistema adaptativo de auto-organización que le permita aprender y adaptarse para enfrentar la falta de certezas y las sorpresas (Adger et al. 2005).

Existe consenso en la literatura sobre el concepto de resiliencia como una capacidad social que permite transformar, adaptar y superar los cambios y perturbaciones ambientales. De esta forma, las comunidades resilientes son menos vulnerables a los riesgos (Cutter et al. 2008), pero esta capacidad puede ser amenazada por la magnitud de las amenazas naturales y por las debilidades de su organización social; sin embargo, también puede ser fortalecida por acciones gubernamentales $y$ comunitarias destinadas a aumentar su resiliencia. En este proceso es fundamental la consideración de los conocimientos locales, la existencia de memoria social (especialmente cuando estos fenómenos han ocurrido con anterioridad en los mismos lugares), el mantenimiento de prácticas, valores y cosmovisiones, y la existencia de instituciones formales e informales que organizan la capacidad de reacción de las comunidades. El capital social es fundamental para fortalecer la resiliencia de la sociedad local (Adger, 2003), así como también el acceso a opciones de tecnología para favorecer la adaptación, la disponibilidad de recursos, criterios democráticos para la toma de decisiones, el stock de capital humano incluyendo la educación y la seguridad personal, acceso a sistemas de diseminación del riesgo y a información desde las instituciones a la sociedad, entre otros, permiten el entendimiento comunitario de las situaciones de riesgo y la anticipación de respuestas (Fraser et al. 2003)

Consecuentemente, la naturaleza no causa "desastres naturales", sino que es la ineficiencia de las relaciones entre ésta y la sociedad (lo que se entiende como medioambiente), que se manifiesta en una falta de adaptación y planificación a la coevolución de ambos componentes de la realidad, que afecta a la vida humana y sus medios de subsistencia. Los desastres, en estas perspectivas, pueden ser evitados, mitigados sus impactos, planificadas sus respuestas y modificadas las conductas humanas ante su ocurrencia.

\section{La construcción social de la Patagonia}

En el caso de Chile, existen poblaciones más vulnerables que otras frente a amenazas como erupciones volcánicas, terremotos e inundaciones. Este hecho está lejos de ser una causa natural, sino que corresponde a una larga historia de desigualdades que requieren cambios radicales. En el espacio urbano, el valor del uso del suelo es menor en áreas de riesgos naturales, por tanto, las poblaciones vulnerables se asientan en ellas. En los espacios rurales, la localización de las poblaciones vulnerables viene dada por la disponibilidad y el acceso a recursos críticos (suelos y agua por ejemplo). Muchas de las ciudades más importantes de Chile han sido afectadas por numerosos terremotos y tsunamis, e incluso destruidas, en los últimos cuatrocientos años. Pelling (2003) relaciona este fenómeno directamente como legado de las lógicas coloniales que construyeron el espacio habitable del Tercer Mundo, y cuyo principal motor fue favorecer el despojo de recursos desde los territorios conquistados, acompañado en muchos casos por el exterminio o erradicación de la población originaria. En este análisis, los asentamientos urbanos fueron construidos sin tomar en cuenta las características geográficas, y el conocimiento local ancestral fue erradicado de la toma de decisiones por irracional o no-económico.

La ecología política, principalmente aquella influenciada por el post-estructuralismo, ha integrado en sus análisis elementos provenientes de las teorías postcoloniales, para explicar por qué algunos territorios pueden ser despojados económicamente y su población anulada culturalmente. Dichosanálisis se centran en entender la situación actual de ciertos territorios a partir del estudio de cómo histórica y culturalmente estos han sido construidos, a través de discursos y prácticas 
hegemónicas de carácter imperialista (Davis, 2009; Offen, 2004). Estas relaciones coloniales han producido injusticias socio-territoriales que han sido naturalizadas por la sociedad (Mann, 2009); es decir, los cambios medioambientales, ya sean sociales o como resultado de las amenazas naturales, ocurren en espacios donde habitan las clases, las etnias, y otros grupos sociales subalternos (Ekers, 2009). Las consecuencias de esto es que los gobiernos tienen concepciones erradas sobre el medioambiente de los "otros", producto de estas desigualdades estructurales (Braun, 2007).

Desde los 1990s, diversos estudios han mostrado como el Estado y el Mercado han clasificado y controlado el territorio de acuerdo a sus propios intereses derivados del colonialismo y las interpretaciones que ha hecho el neoliberalismo, en desmedro de los habitantes y ecosistemas locales. Esto ha permitido vaciar al territorio de contenido histórico para ser recreado de acuerdo a los intereses de los grupos dominantes (Bryant, 1994; Neumann, 1998; Braun, 2002). Estos territorios pueden ser entendidos como "construcciones ecológico-discursivas" (Peet et al. 2004), es decir, espacios, paisajes, medioambientes y lugares construidos desde los sitios de poder externos a ellos (Neumann, 2010). En este tipo de conceptualizaciones se enmarca la acción del Estado, con una epistemología específica en cuanto a los habitantes, recursos naturales y estrategias de desarrollo que dichos territorios deben seguir. En este tipo de relaciones postcoloniales, ciertos territorios aparecen "vacíos-pero llenos" de recursos naturales, construcción cultural que favorece la expansión (Bridge, 2001), por ejemplo, de la industria extractiva y de actividades como el turismo. El Oriente (Said, 2003), los trópicos (Bowd \& Clayton, 2005; Arnold, 2000), la Antártica (Glasberg, 2012; Dodds, 2012), y la Amazonía (Slater, 2002), han sido culturalmente construidos para favorecer ciertos intereses político-económicos.

La Patagonia también puede ser entendida como una construcción cultural para favorecer determinadas prácticas de poder material y simbólico, que han favorecido un determinado tipo de colonización y explotación (Romero Toledo, 2014a, 2014b; Irarrázaval, 1930, LivonGrosman, 2003; Casini, 2007; Peñaloza, 2010).
Desde el imperialismo occidental, la Patagonia ha sido culturalmente construida como un territorio gigante, que pertenece más al mundo de lo natural que al social, con características sobrenaturales más que reales. Chile y Argentina copiaron dichas conceptualizaciones, y reprodujeron la idea de un territorio vacío y prístino, sus habitantes fueron caracterizados en una condición subalterna que permitió su exterminio y erradicación (LivonGrossman, 2003), y sus tierras como "malditas" e improductivas (Vicuña Mackenna, 1880), para favorecer la idea de un territorio no ocupado. Esto permitió la desposesión de recursos naturales y la territorialización por parte de los Estados postcoloniales, de manera similar a como ha ocurrido en otras partes del mundo (Harris, 2004; Vandergeest \& Pelusso, 1995).

De esta manera, desde el laudo arbitral de 1902 entre Chile y Argentina, la Patagonia, especialmente su sección Occidental, ha sido tratada como un espacio subalterno, despoblado y listo para ser intervenido, principalmente por grandes capitales extranjeros, con intentos de colonización dificultados por su condición geográfica (Martinic, 2001, 2005; Ivanoff, 2007). Desde mediados del siglo XX, el Estado chileno realizó un proceso de chilenización a través de infraestructura pública mínima, la instalación de instituciones, y la remoción de los nombres de ciertos hitos geográficos, orientado a la incipiente colonización espontánea. La influencia política de la Patagonia Occidental ha sido mínima, y cómo sostiene Ibáñez (1973), se le ha dado el trato de una provincia pobre y aislada, situación que continua hasta el día de hoy. Durante la dictadura militar, y presionado por problemas limítrofes con Argentina, el Estado empezó la construcción de la Carretera Austral y reforzó el proceso de colonización aumentando la presencia militar en la zona. Con la vuelta de la democracia, los planes de desarrollo de la Patagonia Occidental se han orientado a proteger sus "condiciones naturales" para el desarrollo del turismo, y a la apertura de sus medioambientes para proyectos extractivos y cultivos centrado en la pesca industrial, salmonicultura e hidroelectricidad, todas iniciativas a partir del capital privado, que han generado conflictos socio-ambientales de importancia nacional.

En la actualidad, la sección occidental de 
la Patagonia es el territorio menos habitado de Chile, no cuenta con una universidad regional, está desconectada por tierra del resto del país, depende fuertemente de la escasa inversión estatal y reposa en emprendimientos privados. Ha sido construida culturalmente como una "zona extrema", es decir, una suerte de colonia chilena, con habitantes de segunda categoría que deben protagonizar conflictos sociales para poder ser visualizados, $y$ que no cuenta con planes gubernamentales para su desarrollo en el corto, mediano o largo plazo.

\section{Erupciones Volcánicas en la Patagonia}

En el territorio chileno se emplazan más de 2.000 volcanes, de los cuales, aproximadamente 500 son geológicamente activos y más de 60 presentan registros eruptivos históricos en los últimos 450 años (Albornoz \& Romero, 2013, 2015). Entre los casos más emblemáticos de manifestación volcánica activa en Chile durante los últimos veinticinco años, se pueden mencionar: Lonquimay (1988), Hudson (1991), Láscar (1993), Chaitén (2008), Complejo Puyehue-Cordón Caulle (2011) y Copahue (2013).

Como señala el historiador Mateo Martinic (2008), la falta de conocimientos sobre la Patagonia, ha incentivado la creencia de que los volcanes en dicho territorio están inactivos, y comúnmente se pasa por alto que en esta región confluyen e interactúan las tres placas tectónicas: Nazca, Sudamericana y Antártica. Testimonio de erupciones volcánicas pueden ser encontrados en el relato del Padre Jesuita José García referido desde Chiloé hacia el sur durante el siglo XVIII (Anuario Hidrográfico de Chile, 1889), o en el relato de Musters (1911) a raíz de la información recolectada desde los Tehuelches en el siglo XIX, como también en otros informes de exploradores y colonos. Sin embargo, el conocimiento sigue siendo precario, y esto se debe principalmente a la incorporación tardía de la Patagonia al Estado Colonial y posteriormente al Estado Nación, al exterminio y asimilación de su población indígena, a la forma en la cual fue colonizada la Patagonia, a través de la ocupación de grandes extensiones de tierra para la producción ganadera, al asentamiento espontáneo de colonos desde fines del siglo XIX (Bertrand, 1886; Steffen, 1910; Pomar, 1923) y a la conformación de localidades dispersas, las cuales fueron posteriormente formalizadas o fundadas por el Estado chileno (Ibáñez, 1973; Martinic, 2001, 2005; Ivanoff, 2002, 2007). De esta manera, no es de extrañar que las erupciones del Hudson (1991) y el Chaitén (2008) tomaran por sorpresa a los habitantes y a las autoridades, que se improvisaran acciones (Albornoz \& Romero, 2013, 2015), y que se fortalecieran discursos sobre la naturaleza indomable de la Patagonia para justificar la falta de acción estatal.

\section{La Erupción del Volcán Hudson}

El desastre causado por la erupción del Volcán Hudson (1991) fue el primer desastre socio-natural de importancia del retorno a la democracia en Chile, cuando las Fuerzas Armadas, especialmente el Ejército, seguían bajo el mando del ex Dictador Augusto Pinochet. La militarización de la zona se puede observar en la toponimia asignada a los lugares. La Patagonia, especialmente la región de Aysén, había sido rebautizada con el nombre de Región del General Carlos Ibáñez del Campo, creándose las Provincias de General Carrera y Capitán Prat, en el contexto de la regionalización y en medio de conflictos geopolíticos con Argentina, para lo cual existieron políticas de colonización dirigida, chilenización de sus características sociales y geográficas, construcción de infraestructura como la Carretera Austral (llamada "Capitán General Augusto Pinochet Ugarte"), y aumento de la presencia militar en la zona (Romero Toledo, 2014b). La respuesta del gobierno de la época frente a la erupción del Hudson fue descoordinada por ausencia de planes de emergencia, desplegando una serie de instituciones civiles y militares en un lapsus de cuatro a ochos semanas, entre ellas la Oficina Nacional de Emergencia (ONEMI), el Servicio Agrícola Ganadero (SAG), el Instituto de Desarrollo Agropecuario (INDAP), el Servicio Nacional de Geología y Minería (SERNAGEOMIN), el Ministerio de Minería y la Dirección General de Agua (DGA), entre otras.

Los registros geológicos muestran que el volcán Hudson tuvo al menos doce grandes erupciones en el Holoceno. Solamente con la erupción de 1971, la primera desde la colonización de esta sección de la Patagonia, se descubrió 


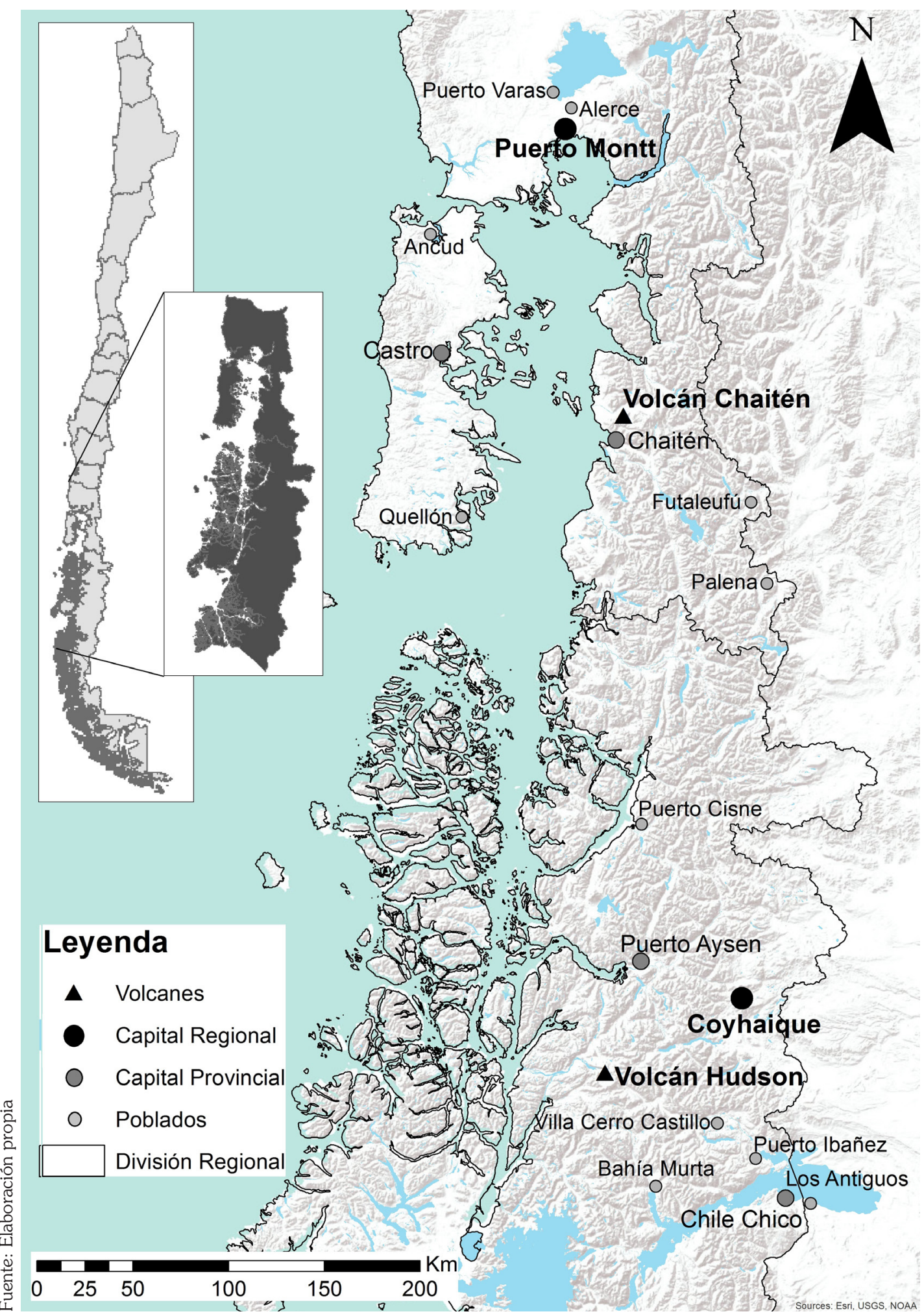

Fig. 1. Localización de los volcanes Hudson y Chaitén 
que el cerro Hudson era en realidad un volcán, tras un evento eruptivo moderado, donde cayó ceniza en las localidades de Coyhaique, Puerto Aysén, Puerto Ibáñez, Chile Chico y Los Antiguos en Argentina (Fig.1). Sin embargo, a pesar del moderado impacto, esta erupción dejó un total de cinco muertos y un desaparecido, junto con cerca de cuatrocientos damnificados, produciéndose una avalancha en la zona de Valle de Huemules (Cayupi \& Abumohor, 1996). De acuerdo a los informes, la ganadería se vio fuertemente afectada por la pérdida de ovinos y la agricultura tardó dos temporadas en recuperarse. Durante el evento, los evacuados, especialmente los niños, fueron conducidos hacia Coyhaique, la capital regional, y localizados en una escuela cercana.

La erupción de 1991 fue solamente evidente cuando el hongo de cenizas pudo ser observado desde Coyhaique, lo que demuestra la ausencia de equipos de monitoreo, aun cuando entre ambas erupciones habían transcurrido solamente veinte años. La erupción fue acompañada de temblores, tormentas eléctricas, lluvias torrenciales de agua, ceniza y material proveniente del interior de la tierra, y un lahar que descendiendo desde el Valle Huemules llegó hasta el mar (Cayupi \& Abumohor, 1996). La pluma, que alcanzó más de 12 mil metros de altura, afectó directamente por precipitaciones de pómez a las localidades de Bahía Murta, Villa Cerro Castillo, Puerto Ibáñez y Chile Chico, mientras la lluvia de ceniza alcanzó principalmente a la Provincia de Santa Cruz en la Patagonia Argentina, donde se localizan grandes estancias ganaderas. Se calcula que en Chile fueron afectadas cerca de siete mil personas, y 473 de ellas tuvieron que ser evacuadas. Esta erupción fue considerada la segunda más violenta del siglo XX en los Andes chilenos, después de la del volcán Quizapu el año 1932 (Naranjo, 1991). La lluvia de cenizas afectó miles de hectáreas en ambos países, hasta dejarlas a obscuras, frente a una población que no tenía los medios para protegerse del material particulado y de la falta de oxígeno, y que evacuó con dificultad los lugares, ante la incertidumbre de no saber si volverían a sus tierras. Las cenizas se mantuvieron en suspensión durante meses, contaminando los recursos hídricos, los suelos, la vegetación y los animales, especialmente el ganado lanar. La acción de las cenizas ricas en circe, álcalis y fósforo, sobre la salud de las personas, no tuvieron un efecto tóxico inmediato; sin embargo, las manifestaciones a largo plazo aún están en estudio. En el caso de Chile, 750.000 hectáreas resultaron directamente dañadas, impactando en el largo plazo al $47 \%$ de la masa ganadera de la zona (Cayupi \& Abumohor, 1996).

Las alteraciones al medio biofísico causadas por esta erupción fueron significativas. Según Borgel (1992), la temporada estival que siguió a la erupción fue rica en precipitaciones y el invierno fue seco, sin lluvias sostenidas. Esto contribuyó a afectar la actividad agrícola y ganadera en la zona, junto con las transformaciones ecológicas, y los impactos de la erupción sobre la vegetación y las aguas. Besoain et al. (1995), evaluaron que las cenizas volcánicas no tenían altos componentes tóxicos y que en la cuenca del Lago General Carrera el suelo tardó un par de años en recuperarse, principalmente con la ayuda de maquinaria; no así en la zona del alto río Ibáñez, donde había población pobre, y la acumulación de material no posibilitaría el desarrollo agrícola, forzando el cambio de uso del suelo de agrícola-ganadero a forestal. Actualmente, es posible encontrar en la región de Aysén bosques muertos que fueron afectados por la lluvia de ceniza, y en ciertos tramos de la carretera, un tipo específico de suelo endurecido que se asemeja al cemento.

En una serie de estudios más detallados realizados el año 2008, un grupo de investigadores neozelandeses evaluó los efectos de la "tormenta de cenizas" en la Patagonia chilena y argentina producida por el Hudson y la acción de los fuertes vientos, que duraron hasta seis meses después de la erupción, alterando la vida de los habitantes locales que tenían que buscar constantemente refugio. De la misma forma, el 2008 se observaban pequeñas dunas de cenizas de entre 10 a 20 centímetros en localidades como Cerro Castillo y en las partes bajas del Valle del Río Ibáñez, y de más de 2 metros en Puerto Ibáñez (Wilson et al. 2011a). De acuerdo a diversos informes, la mortandad en ganado ovino superó el millón de animales y a varios miles de ganado bovino en toda la Patagonia, principalmente concentrado en los tres meses posteriores a la catástrofe. La evacuación del ganado de estepa fue casi imposible debido a la lluvia de cenizas lo que limitó la visión. A partir del 
año 2000 la vegetación comenzó a restablecerse, y la actividad hortícola en la cuenca del lago General Carrera comenzó a repuntar solamente seis años después de la erupción.

Una de las áreas más impactadas fue Puerto Ibáñez, donde el río se estancó (Banks \& Ivan, 1991) afectando el delta e inundando cincuenta hectáreas de tierras cultivables y de pastoreo. Posteriormente las lluvias y los vientos siguieron movilizando los residuos volcánicos sobre la cobertura vegetal de la zona y creando dunas. El viento y las cenizas continuaron actuando sobre la localidad de Puerto Ibáñez de forma cotidiana, impactando las residencias localizadas en la sección sudoeste, actividades como los invernaderos (Wilson et al. 2011a) y la disposición y uso de agua para irrigar y beber, la cual corre por canales abiertos desde fuentes naturales ubicadas al norte de la ciudad (Wilson et al. 2011b). Después de un lapsus de tres a cuatro años, los habitantes de la zona que habían sido evacuados volvieron a asentarse en las áreas afectadas, lo que ya habían hecho de forma esporádica durante dicho período.

En términos del trauma psico-social, el cambio radical del paisaje cotidiano, producido por la muerte del ganado, los días de oscuridad, la transformación de la praderas producto de la cubierta de cenizas, las dificultades de acceso a agua, el miedo y el encierro, la falta de mecanismos de control y alerta, y el declive de la actividad agrícola y ganadera producida en los años posteriores a las catástrofe, redujo en un $30 \%$ la población de Puerto Ibáñez y generó el abandono de las granjas, dada la falta de capacidad financiera de la población, especialmente en los sectores de más avanzada edad (Wilson et al. 2011b). Sin embargo, cinco años después de la catástrofe, las granjas comenzaron a ser re-ocupadas, algunas de ellas con plantaciones de pino, lo que se asocia a la recuperación natural de los suelos, y no necesariamente a las medidas gubernamentales, ofrecidas, por ejemplo, a través de los créditos entregados por el Instituto Nacional de Desarrollo Agropecuario (INDAP) (Wilson et al. 2012).

Las medidas del gobierno apuntaron a otorgar créditos y planes de manejo agrícola, pero no para el re-asentamiento de granjeros o para aquellos, de estos últimos, que no eran dueños de la tierra, o que contribuyeran a generar un mercado para las áreas devastadas. Lo que sí ocurrió fue la compra a bajo precio de las parcelas localizadas a sesenta kilómetros del volcán (Wilson et al. 2011b). El apoyo gubernamental en la zona, debe ser entendido en el contexto de las relaciones de dependencia y vulnerabilidad que tiene esta población, históricamente aislada y marginada. De la misma manera, las medidas de cambio de técnicas de cultivos durante el postdesastre y la incorporación de invernaderos han sido más bien limitadas. El caso contrario son aquellos productores que han tenido la capacidad de acceder a maquinaria para remover las cenizas, construir cortinas cortaviento e introducir innovaciones.

El desastre causado por la erupción del Hudson, como evento socio-natural, ha determinado la vida de una sección importante de la Patagonia chilena y argentina. Sin embargo, y como se ha señalado en otras investigaciones, la actividad ganadera en la región de Aysén había decaído mucho antes de la erupción del volcán, principalmente por el bajo precio de la carne y la lana. De la misma manera, la falta de infraestructura pública y de una red caminera en buenas condiciones son problemas históricos de este territorio (Romero et al. 2009). Las condiciones de marginación y aislamiento de la Patagonia chilena, dificultaron la evacuación de personas y animales, así como la asistencia para evitar el colapso de las casas por la acumulación de cenizas.

En las políticas de desarrollo para la región de Aysén, desde el año 2000 en adelante, no existe mención al volcán Hudson. Es decir, el desastre socio-natural más importante ocurrido en la historia moderna de la región no es considerado dentro de las políticas públicas regionales. Lo anterior puede deberse al marcado centralismo nacional, a la falta de profesionales de la zona que trabajen en el Gobierno Regional, o a la falta de universidades que realicen investigación a nivel regional. Todos estos elementos son resultado de la marginalidad histórica de la región de Aysén. Pero también puede deberse a que la relación entre la sociedad y la naturaleza haya sido reciclada para transformar la vocación productiva de la zona, hacia el turismo y la producción hidroeléctrica. Esto ha generado que la preocupación sobre el medioambiente regional se oriente hacia su biodiversidad ambiental 
y paisajística con fines económicos, donde el riesgo volcánico ha sido absolutamente invisibilizado.

En la Estrategia de Desarrollo Regional de Aysén (Gobierno de Chile, 2000), elaborada nueve años después de la erupción, y con una sección de la región aún bajo los efectos de las cenizas, el enfoque fue la conservación de la calidad ambiental y la integración del territorio a las dinámicas del país. En términos de seguridad ciudadana, el énfasis estuvo puesto en el control de la delincuencia, campañas de prevención de drogas $y$ alcohol, y el fortalecimiento de los bomberos (Gobierno de Chile, 2000, p. 48). En el caso de la nueva Estrategia de Desarrollo Regional (Gobierno de Chile, 2009), realizada por una alianza entre el Gobierno Regional y la Comisión Económica para América Latina y el Caribe-Instituto de Planificación Económica y Social (CEPAL-ILPES), existe un área específica para geomorfología, donde, sin embargo, no se hace mención al Volcán Hudson; es más, se menciona que el riesgo natural de la región es la "erosión por hielo" (Gobierno de Chile, 2009, p. 25); tampoco aparece la presencia de riesgo volcánico como una limitación para la actividad ganadera y turística ni se hace mención a éste en el reciente "Plan Aysén" 2010-2014 (Gobierno de Chile $\mathrm{s} / \mathrm{f}$ ) donde la relación de la región con su medioambiente se reduce solo al ámbito de la contaminación ambiental de Coyhaique.

En contraste con esta invisibilización de parte de la política pública regional, la zona del volcán Hudson fue declarada en alerta roja el año 2011 por la ONEMI, el Ministerio de Minería y el SERNAGEOMIN, debido a una serie de sismos, la presencia de una pluma de 3 kilómetros de altura proveniente de un cráter distinto al de la erupción de 1991, un lahar en el río Huemules y en el río Sorpresa hacia el Océano Pacífico, y una fisura en el volcán de alrededor de 800 metros. Se constituyó un Comité de Emergencia Regional, para coordinar las acciones civiles y militares, que llevó a la evacuación de 128 habitantes en el radio de influencia de 40 kilómetros a la redonda en menos de seis horas, los cuales fueron relocalizados principalmente en casas de familiares y empresas salmonícolas de la zona. Se distribuyeron mascarillas frente a la presencia débil de cenizas, fue notorio el aumento de lodo, piedras y troncos en los ríos y se instalaron cuatro estaciones de monitoreo de sismos. La reacción fue rápida, principalmente debido a las críticas a la lentitud y descoordinación sobre como actuó el gobierno frente al terremoto de 2010. Pese a lo anterior, el riesgo volcánico es ignorado sistemáticamente en los planes de desarrollo regional. Esto es grave, dado que en cuarenta años el volcán Hudson ha tenido tres erupciones.

\section{La Erupción del Volcán Chaitén}

El Volcán Chaitén y el Volcán Hudson están separados por alrededor de 340 kilómetros de distancia. Dichos volcanes están conectados por la falla "Liquiñe-Ofqui", junto con otros macizos como el Llaima, Villarrica, Mocho-Choshuenco, Corcovado, el Macá y el Puyehue. Al igual que en el caso del Hudson, la erupción de Chaitén debe ser contextualizada dentro del casi inexistente conocimiento sobre los volcanes patagónicos (pese a que dicho volcán aparece identificado en "Volcanes de Chile" de González-Ferran, 1995). Estudios posteriores a su más reciente erupción muestran que este volcán ha tenido al menos cinco erupciones durante el Holoceno, la penúltima ocurrida hace más o menos 320 años (El Mercurio, 30 de Mayo de 2010), lo que hace necesario revisar los registros del proceso de colonización, especialmente aquellos producidos por los Jesuitas desde la Misión de Chiloé.

El $1^{\circ}$ de mayo de 2008, más de cincuenta sismos se registraron en la zona, para posteriormente pasar a una fase de erupción del tipo Pliniana con grandes emisiones de pómez y gases que afectaron principalmente a los valles (Gobierno de Chile, SERNAGEOMIN, 2008; Gobierno de Chile, ONEMI, 2009). La erupción presentó riesgos debido a la existencia de pendientes fuertes y la posibilidad de que la remoción en masa y lahares afectaran a la planicie, donde se emplaza la ciudad de Chaitén (González, 2011), o que la pluma de cenizas colapsara por falta de presión, y cayera sobre dicha ciudad. La erupción del Chaitén se caracterizó por una enorme columna eruptiva que se elevó por sobre los 40 kilómetros, decretando una alerta roja que se mantuvo hasta junio de 2010. Se produjeron tormentas eléctricas y una lluvia de cenizas con material particulado que midió menos de $4 \mu \mathrm{m}$ y que pudo afectar la salud de las 
personas (Zarges, 2008). Las cenizas del Chaitén cubrieron alrededor de 116 mil kms ${ }^{2}$ con más de 2 centímetros, y más de 25 mil kms ${ }^{2}$ con más de 3 centímetros en Chile y Argentina, lo que tardará al menos una década en recuperarse (FADEU, 2008), afectando la capacidad productiva ganadera y forestal de la zona. Según SERNAGEOMIN (2008), la superficie afectada de bosque nativo en las comunas de Chaitén y Hualaihué sobrepasó las 82 mil hectáreas. Los recursos hídricos de la zona fueron cubiertos por la lluvia de ceniza y pómez, especialmente los ríos Blanco, Michimahuida, Yelcho y Rayas, y se afectó el sistema de agua potable rural de la zona.

Debido a que el proceso de colonización de la Patagonia ocurrió desde fines del siglo XIX, y principalmente se consolidó en la segunda mitad del siglo XX, no existía memoria social sobre erupciones volcánicas. De la misma forma, no había estudios sobre erupciones previas que ayudaran a analizar los riesgos o amenazas para la localidad. Frente a este escenario, se estimó que el mayor riesgo era que la columna eruptiva colapsara por pérdida de presión y/o cambio de vientos, y que cayera sobre la ciudad de Chaitén. A partir de este temor, la autoridad ordenó la evacuación total de sus habitantes y la prohibición de regresar hasta que las condiciones lo permitieran. Los habitantes de Chaitén fueron trasladados de manera obligatoria en buques de la Armada de Chile hacia distintos puntos de la región de los Lagos, entre ellos la Isla de Chiloé y a la Región de Aysén.

Al mismo tiempo, producto de la erupción, se desmoronó el domo antiguo del volcán y los flujos materiales se depositaron en el río Blanco. Esto generó el aumento del caudal de dicho río que arrastró el material, acumulándolo en el puente de la ciudad de Chaitén ocasionando un desborde e inundándola. Como la ciudad había sido evacuada y abandonada, no existieron medidas precautorias de limpieza del río. De esta manera, la ciudad de Chaitén fue destruida, no directamente por lahares, ni por los flujos piroclásticos, sino por la llegada de las lluvias intensas del invierno que se encontraron con los cauces fluviales colmatados por las cenizas, lo que provocó el desborde de sus aguas. Como resultado, la ciudad de Chaitén quedó dividida en dos: Chaitén Norte la cual no fue tan afectada por la salida del río, y Chaitén Sur, sección que quedó inundada por las aguas, ceniza y lodo (Jiménez, 2013).

El traslado masivo de población desde la ciudad de Chaitén, su instalación provisoria (o definitiva) en pueblos y ciudades cercanas, el retorno de una parte importante de la población a la ciudad de origen y el abandono de las iniciativas de reconstrucción de un nuevo asentamiento, han abierto un escenario ecológico-político sumamente complejo. La evacuación no contó con planes específicos de mediano y largo plazo, ni tampoco con organismos públicos ni legislaciones que permitieran ejecutar sistemáticamente el conjunto de acciones de evacuación. Tampoco se consideró la inserción social, económica y cultural de los trasladados, ni la mitigación de los efectos sociales y sicológicos negativos del desarraigo y la falta de incertidumbre sobre el retorno (Marchant, 2010; Ugarte \& Salgado, 2012). De esta manera, los erradicados con mayor disponibilidad y acceso a los recursos, se establecieron en las ciudades principales, insertándose con mayor éxito en la complejidad de la vida urbana y beneficiándose de las redes de servicios públicos, mientras que los sectores más vulnerables, tendieron a hacerlo en pueblos pequeños, bajo el amparo sustancial de las redes familiares y practicando la continuidad de sus actividades laborales, concentradas especialmente en pesca y silvicultura.

Las investigaciones mencionadas incluyen relatos de los actores que dan cuenta de relaciones espaciales, sociales y culturales que en forma idealizada o real, supuestamente vinculaban de manera especialmente armoniosa a los habitantes de Chaitén con su territorio, entre ellos como comunidad social, y con sus lugares de residencia, correspondientes a paisajes caracterizados por gran belleza natural, donde compartían modos de vida, seguridad y tranquilidad. Todos estos valores altamente positivos otorgados a sus lugares de origen, eran contradictorios con las escasas cualidades reconocidas a aquellos donde fueron forzados a residir después de la evacuación. Esta reacción negativa permite explicar, por un lado, la insatisfacción general con los procedimientos para su atención implementados por el Estado, no obstante que les fueron otorgadas significativas ayudas económicas, albergues para enfrentar la emergencia, bonos para arrendar viviendas, dinero 
para la manutención de las familias y becas para los estudiantes, además de contención sicológica. Es evidente que los beneficios económicos no alcanzaron a compensar las pérdidas asociadas a la ontología de los lugares ni a las deficiencias morales con que se enfrentan los desastres socio-naturales.

En gran medida, la angustia e incertidumbre manifestada por los trasladados ha estado relacionada con la desarticulación de sus redes y tejidos sociales, causada tanto por la dispersión espacial de la comunidad en diferentes pueblos y ciudades, como por las dificultades de insertarse en nuevos modos de vida, más urbanos, y que abarcaron la totalidad de sus componentes, incluyendo subsistencia, alimentación, vivienda, educación, trabajo, relaciones sociales, exposición a una nueva cultura (Ugarte \& Salgado, 2012). En estrecha relación con este proceso de generación de incertidumbre que acompañó la evacuación, debe ser también entendida la problemática de la decisión sobre el lugar de reconstrucción de Chaitén, en su sitio original, o su traslado a un lugar que ofreciera mejores condiciones de seguridad.

Estudios de la Pontificia Universidad Católica, de la Universidad Austral de Valdivia y de la consultora internacional ARUP, revelaron la exposición de la ciudad de Chaitén frente a numerosas amenazas naturales, lo que se materializó en una propuesta de refundación en otro lugar, y con el inicio de la instalación de servicios básicos para atraer y asistir a la población evacuada e impedir su retorno a la ciudad original, tales como oficinas municipales, dependencias policiales y una pista de aterrizaje. De esta manera "Nueva Chaitén" iba a ser construida en la localidad de Santa Bárbara, emplazada a 11 kilómetros de la ciudad destruida, como parte de un Plan Maestro (2010) diseñado por el gobierno y que incluía componentes de participación ciudadana para los erradicados de Chaitén localizados en las regiones de los Ríos, Los Lagos y Aysén. La elaboración del Plan Maestro se constituyó en una herramienta de planificación sin precedentes en Chile, donde los vecinos y actores sociales de Chaitén diseñaron la nueva ciudad a la cual querían volver a vivir, que contemplaba espacios públicos grandes e integrados al entorno natural como plazas, calles y costanera, en los cuales los Chaiteninos proyectaron actividades económicas, sociales y culturales, destacando el turismo, el uso de energías renovables y criterios de sustentabilidad (Gobierno de Chile, 2010).

En abril de 2011, el Gobierno de la época, presionado por los altos costos de la construcción de una nueva ciudad en la localidad de Santa Bárbara y la escasa incidencia política de esta pequeña población local, junto a la necesidades de la reconstrucción de la sección centro-sur de Chile afectada por el terremoto y tsunami de febrero de 2010, revirtió la idea de construir la ciudad "Nueva Chaitén", y propuso su re-localización en la parte norte del mismo sitio afectado por la erupción de 2008, con el fin de ahorrarle recursos al fisco. Catalina Parot, Ministra de Bienes Nacionales de la época declaró que la habilitación de Chaitén Norte con un presupuesto de más de 4 mil millones de pesos era "una propuesta realista, que toma en cuenta lo que realmente quiere la gente que está habitando allá. El proyecto de Santa Bárbara era teórico, pero la verdad es que nadie quería trasladarse hacia allá" (Parot, 2011). Este nuevo episodio contempló la adquisición por parte del Estado de las viviendas de la sección sur de Chaitén, las cuales habían sido abandonadas por el peligro al cual estaban expuestas frente a un evento natural de similares características. El denominado programa "Solución Chaitén Norte" planteaba que la ciudad era habitable y transitable, para lo cual se ordenó la instalación de los servicios básicos, aumentar la dotación de policías, mejorar la conectividad marítima y terrestre y habilitar una pista de aterrizaje. De esta manera, Sebastián Piñera, Presidente de Chile 2010-2014, declaró: "las familias que tuvieron que evacuar Chaitén, más de 6 mil familias, el año 2008, tendrán la oportunidad, si así lo quieren, de volver a la tierra que los vio nacer" (Piñera, 2011).

Sin embargo, el informe de las Naciones Unidas, "Diagnóstico de la Situación de Reducción del Riesgo de Desastres Naturales en Chile" (ONU, 2010), advirtió sobre la necesidad de reducir los factores subyacentes al riesgo, específicamente a través de la planificación territorial. Por su parte, el "Diagnóstico Estado de la Reconstrucción Erupción Volcán Chaitén" (Ministerio del Interior y Seguridad Pública, 2014) señala que la ciudad presenta claros signos de abandono y que es necesario tomar medidas para mitigar riesgos inminentes, toda vez que en ella viven 1.180 personas en la 
sección Norte, y 552 personas en el sector sur, que no debería estar habilitado, y que se encuentran en condiciones de toma de terrenos y viviendas. Según dicho informe, el SERNAGEOMIN siempre ha alertado sobre el riesgo que representa Chaitén (Gobierno de Chile, 2014, p. 50).

Frente a las contradicciones de las políticas y actuaciones públicas que ilustra el caso de Chaitén, los habitantes y la comunidad han empezado de manera informal e ilegal la reconstrucción de su ciudad. Este hecho no debería ser una sorpresa, dado que sigue los patrones de ocupación de la Patagonia Chilena, la cual ha sido construida principalmente a través del esfuerzo individual y de las redes comunitarias, las cuales posteriormente fueron reconocidas y apoyadas por el Estado. Tampoco debería sorprender esta forma de reconstrucción urbana dentro del contexto Latino Americano, donde la toma de terrenos, la ocupación ilegal de viviendas, las conexiones ilegales de electricidad y agua potable, y la construcción informal de alcantarillados, entre otras, han sido la vía en la cual las poblaciones vulnerables han reclamado su espacio en la ciudad. Por el contrario, se debería reconocer la enorme capacidad de resiliencia que tienen las poblaciones vulnerables para levantar literalmente desde las cenizas sus casas y barrios. Esto se aprecia tanto en el caso de Chaitén, como en las áreas afectadas por el Hudson, aquellas destruidas por el terremoto y el tsunami de 2010 y anteriores, y nuevamente en la reconstrucción post-incendio de Valparaíso en 2014. Es precisamente esa capacidad de adaptación y resiliencia de los grupos vulnerables, especialmente en un territorio excluido como la Patagonia, lo que debería concentrar los esfuerzos de prevención de riesgo y reconstrucción pre y post catástrofe. Porque mientras los gobiernos, y agencias internacionales discutían sobre dónde, cómo y cuánto iba a costar reconstruir Chaitén, los ex habitantes, pero también otros nuevos que han venido llegando, empezaron una reconstrucción silenciosa, invisible a la política pública, con otros tiempos sociales y otras dinámicas.

\section{CONCLUSIÓN}

Este artículo ha indagado sobre la estrecha relación que existe entre las amenazas naturales extremos y las vulnerabilidades políticas, económicas, culturales y ambientales de ciertos territorios, como la Patagonia Chilena, empleando un enfoque de ecología política para comprender cómo la sociedad y la naturaleza se interrelacionan, co-constituyen y se afectan mutuamente sobre un territorio y sus lugares, debido a la identidad cultural y apropiación física de los mismos. De esta manera, las amenazas naturales no pueden ser analizadas sin considerar las relaciones sociales y las construcciones culturales. Pero también, la naturaleza no puede ser entendida como algo estático y pasivo, sino como un actante en movimiento que afecta y co-determina la acción social: lo "natural" y lo "social" no pueden ser analizados en forma independiente, sino que como fenómenos multidimensionales y profundamente conectados. Amenazas naturales, riesgos y vulnerabilidades sociales, están interrelacionados con factores socio-económicos, políticos, culturales y ambientales de carácter histórico, que distribuyen a la población de forma desigual sobre el territorio y sus diversas características biofísicas. Las amenazas naturales extremos forman parte del ciclo natural de la tierra, y pasan a transformarse en riesgo cuando la población se asienta espacial y temporalmente en los lugares donde ellos ocurren, lo cual no puede ser separado de las condiciones y circunstancias político-económicas en la que la población está inserta.

Lavulnerabilidad sedistribuyedesigualmente en el territorio, dependiendo de la localización de los distintos grupos sociales, raciales y étnicos. Estos espacios pueden registrar una alta exposición ante amenazas naturales, y por lo tanto, exigirían la permanente preocupación y actuación política, destinada a impedir su ocupación o a mitigar dichos riesgos; especialmente si las poblaciones que se asientan son particularmente sensibles, ya sea por la fragilidad o dinámica de las amenazas naturales o bien debido a la incidencia del aislamiento, falta de accesibilidad a los bienes y servicios, o elevado costos de transporte. La incertidumbre y desconocimiento que existen sobre la dinámica de la naturaleza en las regiones extremas, no han estado acompañados necesariamente de la instalación de instituciones científicas en dichas zonas, como tampoco en la instalación de equipamientos y observatorios ecológico-sociales que den cuenta 
de las transformaciones de los medios naturales y socioeconómicos. La competitividad de estos lugares, en términos económicos clásicos resulta ser claramente insuficiente para apreciar y considerar sus riquezas en cuanto a la pristinidad y diversidad de sus ecosistemas, calidad ambiental y paisajística, así como respecto a sus manifestaciones culturales, todo lo cual exige planes y políticas de desarrollo regional y local diferentes y especializadas en comparación con otros lugares más cercanos al centro del país. Las amenazas naturales forman parte de los ciclos de largo, mediano y corto plazo de estos territorios, y por ello exigen ser tenidas en cuenta en las acciones de intervención humana. Lamentablemente, la historia ambiental de la Patagonia está repleta de desaciertos debido a que la centralización con que se adoptan las decisiones en Chile ha implicado acciones y prácticas alejadas de su realidad. Los incendios forestales que destruyeron miles de hectáreas de bosques nativos y erosionaron sin contemplaciones sus suelos, durante los últimos siglos, pretendían cristalizar un imaginario socio-político carente de realismo, lo que se ha visto repetido con las propuestas más recientes de construir represas hidroeléctricas sin considerar debidamente el estado del medio ambiente natural y la complejidad del medio ambiente socio-económico-cultural. La Patagonia chilena continúa esperando procedimientos $y$ mecanismos que privilegien el protagonismo de las comunidades locales en la construcción de su desarrollo, más allá de meros objetivos económicos. El Estado nacional no dispone hasta ahora de propuestas generales que le permitan asumir la coordinación entre inversiones públicas y privadas como acciones de asociatividad que tienen en las comunidades locales a sus actores fundamentales.

La no consideración de las amenazas naturales y riesgos, por ejemplo, de las erupciones volcánicas que han afectado a la Patagonia en los años recientes, en los planes y estrategias de desarrollo urbano y territorial, y la inexistente preparación de las sociedades locales, dan cuenta de la precariedad de las acciones preventivas, que son la base de una adecuada estrategia de adaptación que evite la ocurrencia de desastres socio-naturales. El país comprende a los eventos extremos de la naturaleza no como parte de ciclos de mediano y largo plazo a los cuáles corresponde adaptarse, sino más bien como hechos fortuitos $e$ incluso metafísicos, de los cuáles hay que preocuparse solamente una vez desencadenados. Mientras las erupciones volcánicas, los sismos y tsunamis, la sequía y las inundaciones, no formen parte de la cultura local y estén debidamente incorporadas en su memoria histórica, continuaran siendo interpretadas como "emergencias" y activando acciones estatales puntuales y efímeras que no llegan a transformarse en aprendizajes sociales capaces de generar políticas y planes ajustados a las circunstancias permanentes de riegos y vulnerabilidades.

\section{AGRADECIMIENTOS}

Hugo Romero Toledo, agradece el apoyo de COES, CONICYT/FONDAP/15130009, del Proyecto FONDECYT de Iniciación $N^{\circ} 11140265$ y del Convenio de Desempeño para la Educación Superior Regional, CDR-UCT 1302. Hugo Romero Aravena agradece a la Iniciativa Milenio del Ministerio de Economía, Fomento y Turismo de Chile. Agradecemos la colaboración de Felipe Gutiérrez y Daniela Triviño quienes aportaron en la elaboración de la cartografía.

\section{BIBLIOGRAFÍA}

Adger, N. (2003). Social Capital, Collective Action, and Adaptation to Climate Change. Economic Geography 79 (4), 387-404

Adger, N. W., Hughes, Terry P., Folke, Carl, Carpenter, Stephen R., \& Rockstrom, J. (2005). Social-Ecological Resilience to Coastal Disasters. Science, 309 (5737), 1036-1039. doi: 10.1126/1112122

Adger, N. (2006). Vulnerability. Global Environmental Change 16, 268-281.

Albornoz, C., \& Romero, H. (2013). Gestión Pública en Chile Frente a la Emergencia Volcánica. Erupciones de los Volcanes Hudson (1991) y Chaitén (2008). Santiago: Centro de Investigaciones en Vulnerabilidades y Desastres Socionaturales (CIVDES).

Albornoz, C., \& Romero, H. (2015). ¿Lecciones aprendidas?: Gestión de Desastres y las Erupciones Volcánicas en Chile. Ponencia presentada en el XV Encuentro de Geógrafos Latinoamericanos. La Habana, Cuba. 1610 de abril de 2015.

Arnold, D. (2000). "Illusory Riches": Representations of the 
Tropical World, 1840-1950.Singapore Journal of Tropical Geography, 21(1), 6-18. doi: 10.1111/14679493.00060

Bankoff, G., Frerks, G. \& Hilhorst, D. (2004). Mapping Vulnerability: Disasters, Development and People. London: Earthscan.

Banks N., \& Ivan M. (1991). United Nations mission to Volcán Hudson, Chile, 20 August to 15 September 1991. Oregon: Report, US GeolSurv, Cascade Volcano Observatory.

Bennett, J. (2010). Vibrant Matter: A Political Ecology of Things. Durham: Duke University Press.

Bertrand, A. (1886). Anuario Hidrográfico de la Marina de Chile. Tomo XI. En A. Bertrand (Ed.), Memoria Sobre la Región Central de las Tierras Magallánicas (pp. 203-343). Santiago: Imprenta Nacional.

Besoain, E., Ruiz, R., \& Hepp, C. (1995). La Erupción del Volcán Hudson, XI Región, y sus Consecuencias para la Agricultura. Agricultura Técnica 55 (3-4), 204-219.

Blaikie, P., \& Brookfield, H. (1987). Land Degradation and Society. New York: Methuen \& Co. Ltd.

Bolin, B. (2006). Race, Class, Ethnicity, and Disasters Vulnerability. En H. Rodriguez, E. Quarantelli \& R. Dynes (Eds.), Handbook of Disaster Research (pp. 113-129). London: Springer.

Börgel, R. (1992). Evidencias del llamado Efecto Invernadero en las Regiones Australes de Chile. Revista de Geografía Norte Grande, 19, 97-103.

Bowd, G., \& Clayton, D. (2005). Tropicality, Orientalism, and French Colonialism in Indochina: The Work of Pierre Gourou, 1927-1982. French Historical Studies, 28(2), 297-327.

Braun, B. (2002). Colonialism's Afterlife: Vision and Visuality on the Northwest Coast. Cultural Geographies, 9(2), 202-247. doi: 10.1191/1474474002eu243oa

Braun, B., (2007). Biopolitics and the molecularization of life. Cultural Geographies, 14(1), 6-28.

Braun, B., \& Castree, N. (1998). Remaking Reality: Nature at the Millenium. New York: Routledge Chapman \& Hall.

Bridge, G. (2001). Resource Triumphalism: Postindustrial Narratives of Primary Commodity production. Environment and Planning A, 33(12), 2149-2173. doi: $10.1068 /$ a33190

Bryant, R., \& Bailey, S. (1997). Third World Political Ecology. London: Routledge Chapman \& Hall.

Bryant, R. (1994). From Laissez-Faire to Scientific Forestry: Forest Management in Early Colonial Burma, 182685. Forest \& Conservation History, 38 (4), 160-170. doi: $10.2307 / 3983602$

Casini, S. (2007). Ficciones de Patagonia: La Construcción del Sur en la Narrativa Argentina y Chilena. Comodoro Rivavia: Fondo Editorial Provincial, Secretaria Cultural del Chubut.

Castree, N., \& Braun, B. (2001). Social Nature, Practice and Politics. Oxford: Blackwell.

Castree, N., Demeritt, D., \& Liverman, D. (2009). Chapter 1. Introduction: Making Sense of Environmental Geography. En N. Castree, D. Demeritt, D. Liverman \& B. Rhoads (Eds.), A Companion to Environmental Geography, (pp. 1-16). London: Wiley-Blackwell.

Cayupi, J., \& Abumohor, J. (1996). Volcán Hudson: Características y Efectos. Oficina Nacional de Emergencia (ONEMI), Departamento de Protección Civil. Santiago: Biblioteca Centro Nacional de Documentación Protección Civil.

Cutter, S., Barnes, L., Berry, M., Burton, C., Evans, E., Tate, E., \& Webb, J. (2008). A place-based model for understanding community resilience to natural disasters. Global Environmental Change 18 (4), 598-606.

Davis, D. (2009). Historical Political Ecology: On the Importance of Looking Back to Move Forward. Geoforum, 40 (3), 285-286. doi:10.1016/j.geoforum.2009.01.001

Demeritt, D. (2009). From externality to inputs and interference: framing environmental research in Geography. Transaction of the Institute of British Geographers, 34 (1), 3-11. doi: 10.1111/j.14755661.2008.00333.x

Dodds, K. (2012). The Antarctic: A Very Short Introduction. Oxford: Oxford University Press, Incorporated.

Eakin, H., \& Luers, A. (2006). Assessing the Vulnerability of Social-Environmental Systems. Annual Review of Environmental Resources 31, 365-394. doi: 10.1146/annurev.energy.30.050504.144352

Ekers, M. (2009). The Political Ecology of Hegemony in Depression-Era British Columbia, Canada: Masculinities, Work and the Poduction of the Forestscape. Geoforum, 40 (3), 303-315.

Escobar, A. (1996). Constructing Nature: Elements for a Poststructural Political Ecology. En M. Peet \& R. Watts (Eds.), Liberation Ecology (pp. 46-68). London: Routledge.

Escobar, A. (1999). After Nature: Steps to an Antiessentialist Political Ecology. Current Anthropology, 40 (1), 1-30.

Fraser, E., Mabee, W., \& Slaymaker, O. (2003). Mutual vulnerability, mutual dependence: The reflexive relation between human society and the environment. Global Environmental Change, 13(2), 137-144. 
Füssel, H. (2007). Vulnerability: A generally applicable conceptual framework for climate change research. Global Environmental Change, 17(2), 155-167.

García, J. (1802). Anuario Hidrográfico de la Marina de Chile, Año XVI. "Diario de Viajes I Navegación hechos por el Padre José García de la Compañía de Jesús”. Santiago: Imprenta Nacional.

Glasberg, E. (2012). Antarctica as a Cultural Critique. The Gendered Politics of Scientific Exploration \& Climate Change. New York: Palgrave Macmillan.

Gobierno de Chile, Servicio Nacional de Geología y Minería (2008). Evaluación Preliminar de los Peligros Geológicos en la Ciudad de Chaitén, Provincia de Palena, Región de los Lagos. Recuperado de http:// www.goreloslagos.cl/gobierno_regional/documentos_ gestion_chaiten.html

Gobierno de Chile. Convenio amplio de cooperación entre el Gobierno Regional de Aysén, Chile, y la comisión económica para América Latina y el Caribe de las Naciones Unidas (2009). Estrategia Regional de Desarrollo de Aysén (EDR). Naciones Unidas, ILPES, CEPAL, Gobierno Regional de Aysén.

Gobierno de Chile. Ministerio del Interior y Seguridad Pública, Oficina Nacional de Emergencia. (2009). Informe Emplazamiento Nueva Chaitén Sector Santa Bárbara- Comuna de Chaitén Región de Los Lagos. Oficina Nacional de Emergencia.

Gobierno de Chile. Ministerio de Planificación y Cooperación. Secretaria Regional de Planificación XI REGION. Estrategia de Desarrollo Regional (EDR) 2000-2006 (2000). Coyhaique: Secretaría Regional Ministerial de Planificación y Coordinación XI Región de Aysén.

Gobierno de Chile. Ministerio del Interior y Seguridad Pública (2014). "Diagnostico Estado de la Reconstrucción Erupción Volcán Chaitén”. Recuperado de http:// www.gob.cl/wp-content/uploads/2014/07/Chaiten_ V5.pdf

Gobierno de Chile (s.f). Plan Aysén 2010-2014. Recuperado de http://www.goreaysen.cl/controls/neochannels/ neo_ch111/appinstances/media43/Plan_Aysen.pdf

Gobierno de Chile. Ministerio de Vivienda y Urbanismo y Red de Protección Social Protege (2010). Plan Maestro Ciudad Chaitén. Recuperado de http://www.plataformaurbana.cl/wp-content/ uploads/2010/04/1270556064_plan_chaiten_ informe_final.pdf

González-Ferrán, O. (1995). Volcanes de Chile. Santiago: Instituto Geográfico Militar.

González, M. J. (2011). Estudio del Impacto Territorial -
Ambiental Generado por la Erupción del Volcán Chaitén (Memoria para optar al título de Geógrafa, Universidad de Chile, Santiago). Recuperada de http:// www.tesis.uchile.cl/tesis/uchile/2011/aq-gonzalez_ $\mathrm{ma} / \mathrm{html} /$ index-frames.html

Harris, C. (2004). Did Colonialism Dispossess? Comments from an Edge of Empire. Annals of the Association of American Geographers, 94(1), 165-182. doi: 10.1111/j.1467-8306.2004.09401009.x

Ibáñez, A. (1973). La Incorporación de Aysén a la Vida Nacional, 1902-1936. Santiago: Historia 11, Instituto de Historia, Universidad Católica de Chile.

Irarrázaval Larraín, J. (1930). La Patagonia: Errores Geográficos y Diplomáticos. Santiago: Imprenta Cervantes.

Ivanoff, D. (2002). La Guerra de Chile Chico o los Sucesos del Lago Buenos Aires. Coyhaique: Editorial Cruz del Sur de la Trapananda-Coyhaique.

Ivanoff, D. (2007). Lago General Carrera: Temporales de Sueños. Santiago: LOM Ediciones.

Jiménez, A. (2013). Los Puntos Cardinales de Chaitén: A propósito de la representación social del territorio. Centro de Documentación CIVDE. Recuperado de http://civdes.uchile.cl/?page_id=52

Latour, B. (2004). Politcs of Nature: How to Bring the Sciences into Democracy. London: Harvard University Press.

Livon-Grosman, E. (2003). Geografías Imaginarias. El Relato de Viaje y la Construcción del Espacio Patagónico. Rosario: Ensayos Crítico, Beatriz Viterbo Editora.

Mann, G. (2009). Should Political Ecology be Marxist? A Case for Gramsci's Historical Materialism. Geoforum, 40 (3), 335-344.

Manyena, S. (2013). Disaster event: Window of opportunity to implement global disaster policies?. Jàmbá: Journal of Disaster Risk Studies, 5 (1), 1-10. doi: 10.4102/ jamba.v5i1.99

Marchant, J. (2010). Proyecto de Práctica Profesional: Lágrimas de Ceniza. Estudio cualitativo sobre la experiencia de desplazamiento de los habitantes de Chaitén, asentados en las ciudades de la Isla de Chiloé y Puerto Montt. Santiago: División de Protección Civil, ONEMI.

Martinic, M. (2001). Braun y Menéndez: Prohombres Patagónicos. Punta Arenas: Ediciones de la Universidad de Magallanes.

Martinic, M. (2005). De la Trapananda al Aysén. Santiago: Pehuen Editores.

Martinic, M. (2008). Registro Histórico de Antecedentes 
Volcánicos y Sísmicos en la Patagonia Austral y la Tierra del Fuego. Magallania, 36 (2), 5-18. Recuperado de http://dx.doi.org/10.4067/S071822442008000200001

Musters, G. (1911). Vida Entre los Patagones. Buenos Aires: Universidad Nacional de la Plata.

Naranjo, J., Moreno, H., \& Banks, N. (1991). La erupción del volcán Hudson en 1991 (46 S): Región XI, Aisén. Chile: Servicio de Nacional de Geología y Minería.

Neumann, R. (1998). Imposing Wilderness: Struggles Over Livelihoods and Nature Preservation in Africa. Berkeley: University of California Press.

Neumann, R. (2010). Political Ecology II: Theorizing Region. Progress in Human Geography, 34 (3), 368-374. doi: 10.1177/0309132509343045

Offen, K. (2004). Historical Political Ecology: An Introduction. Historical Geography, 32, 19-42.

Organización de las Naciones Unidas en Chile, ONU. (2010). Diagnóstico de la Situación de Reducción del Riesgo de Desastres Naturales en Chile. Organización de las Naciones Unidas en Chile.

Parot, C. (2011). En Rienzi, F. (6 de abril 2011). Presidente Piñera relanza la "nueva" Chaitén en enclave distinto al proyectado por Bachelet. El Mercurio. Recuperado de <http://www.plataformaurbana.cl/ archive/2011/04/06/presidente-pinera-relanza-lanueva-chaiten-en-enclave-distinto-al-proyectado-porbachelet/>

Peet, R., \& Watts, M. (1996). Liberation Ecologies: Environment, Development, Social Movements. London: Routledge.

Peet, R., Robbins, P., \& Watts, M.(2011). Global Political Ecology. London: Routledge.

Pelling, M. (2003). The Vulnerability of Cities: Natural Disasters and Social Resilience. London: Earthscan.

Pelling, M., \& Dill, K. (January, 2010). Disaster politics: tipping points for change in the adaptation of sociopolitical regimes. Progress in Human Geography, 34 (1), 2137. doi: 10.1177/0309132509105004

Peñaloza, F. (2010). Myths and Realities: Mapping Scientific, Religous, Aesthetic and Patriotic Quest in Patagonia. In

Peñaloza, F., \& Wilson, J. (Eds.), Patagonia Myths and Realities (pp. 1-25). Oxford: Peter Lang.

Piñera, S. (2011). Piñera dio a conocer "Plan solución Chaitén" y oficializó refundación de la ciudad. Cooperativa. Recuperado de http://www.cooperativa.cl/noticias/ pais/region-de-los-lagos/volcan-chaiten/pinera-dio-aconocer-plan-solucion-chaiten-y-oficializo-refundacionde-la-ciudad/2011-04-09/223055.html
Pomar, J. (1923). Tierras de Colonización: La concesión del Aisén y el Valle Simpson. Santiago: Imprenta Cervantes.

Robbins, P. (2011). Political Ecology: A Critical Introduction. Oxford: Wiley

Romero, H., Fuentes, C., \& Smith, P. (2010). Dimensiones geográficas territoriales, institucionales y sociales del terremoto de Chile de febrero 2010. Cuadernos de Geografía, Revista Colombiana de Geografía, 19, 135-150. doi 10.15446/rcdg

Romero, H., Fuentes, C., \& Smith, P. (2011) La Geografía de los Riesgos "Naturales" y el Terremoto de Chile del 27 de febrero de 2010. En Bocco, G., Urquilla, P. y Vieyra, A. (Coords.), "Geografía y Ambiente en América Latina” (pp. 251-282). México: Centro de Investigaciones en Geografía Ambiental, Universidad Nacional Autónoma de México.

Romero, H., \& Mendonça, M. (2012). Amenazas Naturales y Evaluación Subjetiva en la Construcción de la Vulnerabilidad Social ante Desastres Naturales en Chile y Brasil. Revista Internacional Interdisciplinar INTERthesis, 9 (1), 127-175.

Romero, H., \& Vidal, C. (2014). "Expansión Urbana y Vulnerabilidad Socio territorial ante los Desastres Naturales de la Conurbación Concepción-Talcahuano: Inundaciones de julio de 2006 y del tsunami de febrero de 2010”. En L. F. Méndez (Ed.), Geografía y Sociedad. El Gran Concepción, su origen, su desarrollo urbano y su evolución social (pp. 321-351). Concepción: Ediciones Universidad del Bío-Bío (en prensas).

Romero Toledo, H., \& X. Toledo (2009). El conflicto por la construcción de centrales hidroeléctricas en la región de Aysén en el sur de chile: una construcción analítica de los discurso de los actores a partir de la teoría fundamentada. Revista Geográfica del Sur, 1(1), 7199.

Romero Toledo, H. (2014a). Ecología Política y Represas: Elementos para el Análisis del Proyecto HidroAysén en la Patagonia Chilena. Revista Norte Grande, 57, 161-175.

Romero Toledo, H. (2014b). Environmental Conflicts and Historical Political Ecology: A Genealogy of the Construction of Dams in Chilean Patagonia (A thesis submitted to the University of Manchester for the degree of PhD in Human Geography in the Faculty of Humanities). Recuperado de https://www.escholar. manchester.ac.uk/uk-ac-man-scw:217920

Said, E. (2003). Orientalism. London: Penguin.

Slater, C. (2002). Entangled Edens: Vision of the Amazon. 
London: University of California Press.

Smit, B., \& Wandel, J. (2006). Adaptation, adaptive capacity and vulnerability. Global Environmental Change, 16(3), 282-292.

Steffen, H. (1910). Viajes de Esploracion i Estudio en la Patagonia Occidental (Tomo II.).Santiago: Imprenta Cervantes.

Sullivan, S., \& Stott, P. A. (2000). Political Ecology: Science, Myth and Power. London: Arnold.

Ugarte, A., \& Salgado, M. (2012). Sujetos en Emergencia: Acciones Colectivas de Resistencia y Enfrentamiento del Riesgo ante Desastres; el Caso de Chaitén, Chile. Revista INVI 29 (80), 143-168. doi: 10.4067/S071883582014000100006

Vandergeest, P., \& Peluso, N. L. (1995). Territorialization and State Power in Thailand. Theory and Society, 24(3), 385-426.

Vicuña-Mackenna, B. (1880). La Patagonia. Santiago: Imprenta del Centro Editorial.

Vidal, C., \& Romero, H. (2010). Efectos ambientales de la urbanización de las cuencas de los ríos Biobío y Andalién sobre los riesgos de inundación y anegamiento de la ciudad de Concepción. En L. Pérez \& R. Hidalgo (Eds.), "Concepción metropolitano (AMC). Planes, procesos y proyectos (pp. 287-304). Santiago: Serie GEOlibros N¹4, Facultad de Arquitectura, Urbanismo y Geografía y Centro EULA de Ciencias Ambientales de la Universidad de Concepción e Instituto de Geografía,
Pontificia Universidad Católica de Chile.

Whatmore, S. (2006). Materialist returns: practising cultural geography in and for a more-than-human world. Cultural Geographies, 13(4), 600-609.

Wilson, T., Cole, J., Stewart, C., Cronin, S., \& Johnston, D. (2011a). Ash storms: impacts of wind-remobilised volcanic ash on rural communities and agriculture following the 1991 Hudson eruption, southern Patagonia, Chile. Bulletin of Volcanology, 73(3), 223-239.

Wilson, T., Cole, J., Cronin, S., Johnston, D., \& Stewart, C. (2011b). Impacts on agriculture following the 1991 eruption of Vulcan Hudson, Patagonia: lessons for recovery. Natural Hazard, 57(2), 185-212.

Wilson, T., Cole, J., Johnston, D., Cronin, S., Stewart, C., \& Dantas, A. (2012). Short- and long-term evacuation of people and livestock during a volcanic crisis: lessons from the 1991 eruption of Volcán Hudson, Chile. Journal of Applied Volcanology, 1, 1-11.

Wisner, B., Blaikie, P., Canon, T., \& Davis, I. (2005). At Risk: Natural Hazards, People's Vulnerability and Disasters. Second Edition. London: Routledge.

Zarges, R. (2008). "Contaminación atmosférica agentes físicos. Cenizas y escorias procedentes de la erupción del volcán Chaitén, sus efectos y riesgos de la salud". Recuperado de http://biosafenviroment.files. wordpress.com/2009/03/conaminacion-atmosfericaerupcion-volcan-chaiten.pdf 